\title{
Kiosk: An Innovative Client Centric Approach to Tuberculosis Prevention and Care
}

\section{Janmejaya Samal', Banuru Muralidhara Prasad ${ }^{2 *}$, Subbanna Jonalgadda1, Sripriya Vegendela1, Sarabjit Singh Chadha ${ }^{2}$}

${ }^{1}$ Catholic Health Association of India (CHAI), Hyderabad, India

${ }^{2} \mathrm{~TB}$ and Communicable Disease Department, International Union against Tuberculosis and Lung Disease, South-East Asia Regional Office, New Delhi, India

Email: *bmprasad@theunion.org,drprasadbm@gmail.com

How to cite this paper: Samal, J., Prasad, B.M., Jonalgadda, S., Vegendela, S. and Chadha, S.S. (2018) Kiosk: An Innovative Client Centric Approach to Tuberculosis Prevention and Care. Journal of Tuberculosis Research, 6, 148-155.

https://doi.org/10.4236/jtr.2018.62014

Received: May 4, 2018

Accepted: June 15, 2018

Published: June 18, 2018

Copyright $\odot 2018$ by authors and Scientific Research Publishing Inc. This work is licensed under the Creative Commons Attribution International License (CC BY 4.0).

http://creativecommons.org/licenses/by/4.0/

\begin{abstract}
Kiosk is a client centric drop-in centre for TB information and services established in urban and peri-urban (slum) settings to provide outreach services under project Axshya. The main objective of the study was to demonstrate the efficacy and feasibility of scaling-up of the model to provide TB services. The assessment was carried out with the help of project recording and reporting formats used to document the information and services provided in the Kiosk from April 2016 to March 2017. The results from retrospective data analysis for services provided at 20 kiosks benefited 16,871 clients; of these 11,252 (66.7\%), 1339 (7.9\%), 848 (5\%), 2911 (17.2\%), (1.4\%), 273 (1.6\%) benefited with TB information, Flexi-DOT, sputum-collection-transportation (SCT), counselling, and domiciliary care respectively. Through active case finding (ACF); 126,893 households were visited and 3593 presumptive-TB-patients received SCT services. A total of $329 \mathrm{~TB}$ patients were identified and linked to treatment services of national TB programme. "Kiosk" as a client centric approach would be a novel concept to ensure TB information, TB related services and contribute to ongoing efforts of $\mathrm{TB}$ case finding.
\end{abstract}

\section{Keywords}

Hard-to-Reach, Sputum Collection and Transportation, India, Tuberculosis, Project Axshya

\section{Introduction}

Tuberculosis is a global public health crisis and India alone has $25 \%$ of the global TB burden [1]. TB continues to be a devastating health crisis with more than 300,000 deaths and 2.2 million new cases along with an economic loss of $\$ 23$ bn 
( $£ 14.9 \mathrm{bn}$; $€ 20.3 \mathrm{bn}$ ) each year [2]. Efforts of National TB programme of India to avert deaths by ensuring early detection and treatment is challenged by growing urban population, migration, over-crowding and client driven (behaviour, socio-economic status) and market driven factors (supply-demand factor). Most often client/s would reach public health facility after taking treatment from multiple healthcare providers [3]. Upon reaching the public health facility one has to go through the long waiting hours in out-patient department and, later to see doctor and this is often cited as reasons for delay [4]. Furthermore the analysis of District Level Household and Facility Survey Data (DLHFS 4) highlights, maximum number of TB patients were taking medications from secondary level care centres (district hospitals) [5]. However there is limited literature to inform the actual number of $\mathrm{TB}$ patients taking medications at district hospitals and their treatment outcome. Programmatically, in few states, the first week or first month of directly-observed-treatment short course (DOTS) is provided at the district hospital or secondary level hospital to review the progress, counselling of TB patients and provide additional supplements (if any) to ensure that the patients complete the treatment. Comprehending this operational mechanism, under Project Axshya, a novel client centric approach- "Kiosk" was designed and implemented to create awareness about TB, link to TB prevention, diagnosis and care services. In this paper we elaborate the experience of implementing Kiosk and feasibility of scaling-up of the model.

\section{Subjects and Methods}

\subsection{About the Intervention}

Axshya Kiosk (AK) was designed and implemented as a human interface Kiosk with an aim to support clients who are visiting high-workload health facilities for taking TB treatment and other related services. Based on the operational feasibility and in consultation with TB programme officer-District TB officers (DTOs) the centres were established at health facility and in community with high TB burden. The community kiosk centres were established within $5 \mathrm{~km}$ radius of the health-facility (usually district hospitals) with an aim to reach urban slum population. In addition, conducted Active TB case finding (ACF) exercise in households of catchment area through verbal screening with cough $\geq 2$ weeks as basic criteria (same method was adopted as in Project Axshya) [6].

Axshya Kiosk services are provided from 6 - 7 am in morning to 6 - 7 pm in the evening. During the out-patient department (OPD) service hours i.e., between 9 am - 12 pm or 11 am - 1 pm (depends on functioning hours of facility), clients visiting at OPD were informed about Tuberculosis (TB) prevention and care using interpersonal communication materials. Any client/s who inform volunteer as having symptoms of TB were referred to hospital laboratory for sputum examination. TB patients accessing the services during the OPD hours were counted as facility patients and were counted to have received TB information and excluded from receipt of DOTS service. The information was recorded in 
project reporting formats; name, age, gender, contact details and services provided by volunteer including time of service [refer supplement file S01, reporting formats 01,02 , and 03].

Volunteers at Kiosk centers were provided training on directly observed treatment short course (DOTS) of national TB programme. Any TB patient visiting kiosks were offered DOTS service at his/her convenient timing between 6 -7 am to $6-7 \mathrm{pm}-$ meaning the services are available in flexible timing and this was known as "Flexi-DOTS" concept. Volunteer recorded the information in requisite recording formats of programme as well as in project formats [refer supplement 01 , reporting format 02 ]. In addition volunteers were provided two day training on project activities, TB programme, sputum collection and transportation (SCT), basic counselling services and active TB case finding.

The following services were offered at Kiosk centres 1) client centered drop-in centre for TB information 2) Sputum collection and transportation (SCT) 3) Flexi-DOT (flexi timing at the convenience of TB patient) 4) domiciliary DOTS to bedridden TB patients 5) counselling of TB patients and their family members 6) linking with social welfare schemes of government 7) house-to-house visit for active TB case finding [refer to supplement file S02] 8) provide SCT service for family members of $\mathrm{TB}$ patients visiting to $\mathrm{AK}$ centres (contact tracing). The contact tracing was conducted with consent from TB patient and the TB programme staff (mainly the senior treatment supervisor).

Axshya Kiosks (AK) is implemented across 40 cities under the project and for this study we used the data from 20 AKs [three different states; Chhattisgarh: Bilaspur, Durg, Rajnadgoan ( $\mathrm{n}=4)$, Maharashtra: Nashik and Aurangabad ( $\mathrm{n}=$ 8) and Tamil Nadu: Coimbatore and Salem $(\mathrm{n}=8)$ ]; which were operational under Catholic Health Association of India ((CHAI) - partner in Project Axshya). [Figure 1: Map of India showing AK sites] Data collected under routine project recording and reporting formats were used for retrospective analysis from April 2016 to April 2017. All clients visiting the AK were included in the data collection for receipt of information about $\mathrm{TB}$, and patients visiting during the Flexi-DOT timings were included for receipt of DOT services. Patients visiting during OPD service hours were excluded from receipt of DOT services, however included under receipt of TB information. This data was validated by project staff at the district level. The secondary data used do not have patient identifiers or individuals who received services at AK. We therefore did not seek ethical approval for the study.

\subsection{Results}

A total of 16,871 beneficiaries visited the facility for different types of services as outlined in description of activity. Of these, $66.7 \%(n=16,871)$ beneficiaries visited the kiosk to obtain TB related information (Table 1). The volunteer primarily provided information about basics of $\mathrm{TB}$, health services and facilities available for TB and their role in this direction. Secondly $5 \%(n=16,871)$ of the 


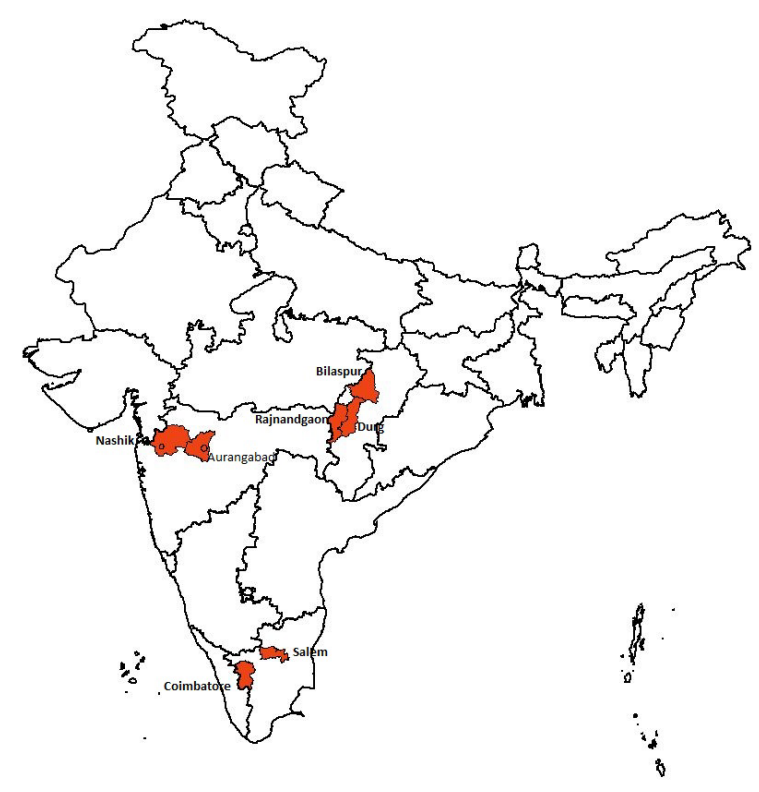

Figure 1. Map of India showing AK sites.

Table 1. Out-put of services provided through Kiosk (April 2016 to March 2017).

\begin{tabular}{|c|c|c|c|c|c|c|c|}
\hline $\begin{array}{c}\text { Total } \\
\text { beneficiaries } \\
\text { offered } \\
\text { services }\end{array}$ & $\begin{array}{l}\text { Beneficiaries } \\
\text { offered with } \\
\text { TB } \\
\text { information }\end{array}$ & $\begin{array}{l}\text { Beneficiaries } \\
\text { offered with } \\
\text { Flexi-DOTS }\end{array}$ & $\begin{array}{l}\text { Total } \\
\text { SCTs } \\
\text { carried } \\
\text { out }\end{array}$ & $\begin{array}{l}\text { Total TB } \\
\text { cases found } \\
\text { through } \\
\text { SCT }\end{array}$ & $\begin{array}{c}\text { TB patients } \\
\text { counselling } \\
\text { services }\end{array}$ & $\begin{array}{l}\text { Domiciliary } \\
\text { care }\end{array}$ & $\begin{array}{c}\text { Contacts } \\
\text { of TB } \\
\text { patients } \\
\text { screened }\end{array}$ \\
\hline 16,871 & $\begin{array}{c}11,252 \\
(66.7 \%)\end{array}$ & $\begin{array}{c}1339 \\
(7.9 \%)\end{array}$ & $\begin{array}{c}848 \\
(5 \%)\end{array}$ & $40(4.71 \%)$ & $\begin{array}{c}2911 \\
(17.2 \%)\end{array}$ & $248(1.4 \%)$ & $\begin{array}{c}94 \\
(0.5 \%)\end{array}$ \\
\hline
\end{tabular}

total beneficiaries got their sputum collected (two samples) in the kiosk which was then carried to the nearest laboratory for examination and the results were then shared with the beneficiaries. Similarly $7.9 \%(n=16,871)$ of the beneficiaries availed anti-TB medication in the form of flexi-DOTS. These patients took their medications under direct supervision of trained volunteer. As a part of domiciliary care $1.4 \%(n=16,871)$ of the beneficiaries were provided with home based services at their door step. Nearly, 17.2\% $(n=16,871)$ of the TB patients received counselling services at the kiosk which was mainly imparted to the TB patients taking anti-TB medications in order to ensure treatment compliance. Through these services at health-facility kiosk, we identified $40 \mathrm{~TB}$ patients (13 female and 27 male) from 848 SCTs. Of all the services provided in the kiosk we were not able to link any TB patient directly with government's social security schemes.

A total of 126,893 households were visited by 80 volunteers who provided information about TB using interpersonal communication materials. The Table 2 delineates the output of ACF services done through kiosks (Table 2). In addition volunteers conducted verbal screening with available members of household (cough $\geq 2$ weeks as criteria). Using the screening criteria, 3593 presumptive TB 
Table 2. Output of Active TB Case (ACF) finding services provided through Kiosk (April 2016 to March 2017).

\begin{tabular}{cccccc}
\hline $\begin{array}{c}\text { Total HHs covered in } \\
\text { ACF }\end{array}$ & $\begin{array}{c}\text { Total SCT } \\
\text { conducted }\end{array}$ & \multicolumn{3}{c}{ Number of TB cases Detected } \\
\hline & & & \multicolumn{3}{c}{ Age group } \\
& \multirow{2}{*}{3593} & 289 & Male: 198 & $<15$ & 07 \\
126,893 & & Female: 91 & $15-60$ & 255 \\
& & & & $>60$ & 27 \\
\hline
\end{tabular}

*ACF-Active Case Finding, SCT-Sputum Collection and Transportation.

patients were identified who's sputum samples were collected and tested at nearest government microscopy centres. Of the 3593 SCTs carried out 2139 (59.53\%) were of male beneficiaries and 1454 (40.46\%) were of female beneficiaries. Through this method a total of $289 \mathrm{~TB}$ patients were identified and were put on DOTS. Among the total 289 TB cases detected 198 (68.51\%) male and 91 (30.53\%) women TB patients. Furthermore the age-wise segregation of the 289 TB cases identified shows 07 (2.42\%), 255 (88.23\%), 27 (9.34\%) cases of pediatric age (up to 14 years), adult ( 15 to 60 years) and geriatric age (more than 60 years) respectively. This also includes 94 SCT conducted through contact-tracing exercise where $4 \mathrm{~TB}$ patients were identified. The treatment services were provided as outlined by the programme guideline.

\subsection{Discussion}

Axshya Kiosk, a novel innovative approach for identifying and linking of presumptive TB patients (PTBPs) at public health-facility and at community. The results highlight that nearly, $8 \%$ of TB patients were identified by examining 4500 PTBPs who could have missed by the system due to high work-load. Secondly, 11,000 beneficiaries at facility-kiosk and 126,893 households at community-kiosk were informed about TB related information and the services available at government facilities (free services) using interpersonal communication tools (IPC). IPC tools are more preferred choice therefore we used "human" interface as one of the key strategy in our kiosk, both at facility and community [7].

Albeit the innovative concept delineated in this research is not exceptionally new in Indian context however the same is very scarcely practiced. One may recall the examples like, "may I help you" kiosk centres which are placed at health-facility to facilitate and direct clients to concerned department. However, these kiosks do not offer any health related information or accompany them for diagnosis by eliciting symptoms especially for TB. Global examples of similar interventions shows positive impact of providing health related information using non-human interface approach [8]-[14]. Similarly, our Kiosks can be placed in healthcare settings and in public places e.g. bus-stops, metro-stations, wherein people can access for any health related information [8] [9] [10] [15]. Drawing 
from these experience we therefore, explored opportunity for establishing a community level kiosk in urban slum areas.

Kiosk at community setting has shown substantial contribution to TB case detection in our study. The services provided is not an alternative to existing community-based TB services, nevertheless it's a complementary to the entire programme wherein the TB prevalence is high, limited access, awareness about TB services and socio-economic factors preventing them from accessing health services [16] [17] [18]. Studies have shown that community kiosks have been useful in providing health education and dissemination of health related services [8]-[14]. Our experience shows that the services at community kiosk need to be designed as per the needs of catchment population for kiosk model to be effective [19].

The contact screening yielded better result which is in lieu with other Indian studies. A similar study in Kolhapur district of Maharashtra highlight that eighteen contacts of 521 (3.45\%) had symptoms suggestive of TB. Of these, 6 contacts were diagnosed with TB; 5 being sputum positive cases and one with X-ray suggestive of TB [20]. Similarly another study in Chennai showed that a total of $29 / 544$ (5.3\%) contacts were found to have TB among whom 23/29 (79\%) were sputum smear positive [21].

Axshya Kiosk is different from usual programme DOT centers where diagnosed TB patients reach the centres for medications; kiosk in addition to providing DOT also provided information and other related services. Through these services, 329 TB patients were diagnosed and were on treatment at these facilities (contact tracing was one of the key feature). Male patients were more than female and this is similar to observation in the National Tuberculosis Programme [22]. We therefore envisage the concept of kiosk to be used to deliver additional services, like counselling, domiciliary care and facilitating in linking TB patients to available social welfare schemes. These were experimented in our study; however, results were appreciable if we had documented the treatment outcomes. This is one of our limitations as there was no regular visit of same client/beneficiary to the centre for taking medications. Secondly, if the patient came in regular OPD hours for DOTS, s/he would be counted in our recording system as regular service and not included in our flexi-DOTS service [the concept was to provide DOTS during non-OPD hours or flexi-hours]. For these reasons we cannot attribute successful outcome of TB treatment to our kiosk. A mix of community based DOTS and community kiosk based DOT is followed and the onus of ensuring treatment completion is on the DOT provider, who is monitored under programme as well as through project. During the intervention few reasons for initial loss to follow up were recognised these include; limited trust in DOTS, adverse effect of drugs, dissatisfaction with public health system, and disbelief in diagnosis are important areas that programme has to address [23] [24]. India, with high TB burden and with goal to END-TB by 2025, some of the out-of-the box innovations is needed. Axshya Kiosk or Kiosk could be one 
such innovation to have a client centric drop-in centre for TB information and services.

\section{Conclusion}

Given the magnitude of the burden of TB in India the role of kiosks in providing TB information and other services is appreciable. Establishment of Kiosks in health-facility and community settings have identified 329 TB patients in addition to the providing DOTS during flexi-timings at health facility, TB information to clients, counselling services, contact tracing and domiciliary visits. Both health-facility and community-kiosk services could reach to a larger section of the community and invariably contribute and compliment the efforts of national Tuberculosis programme.

\section{References}

[1] WHO (2017) Global Tuberculosis Report 2017. http://www.who.int/tb/publications/global_report/en/

[2] Udwadia, Z.F. and Mehra, C. (2015) Tuberculosis in India. British Medical Journal, 23, h1080. https://doi.org/10.1136/bmj.h1080

[3] Satyanarayana, S., Nair, S.A., Chadha, S.S., Shivashankar, R., Sharma, G., Yadav, S., et al. (2011) From Where Are Tuberculosis Patients Accessing Treatment in India? Results from a Cross-Sectional Community Based Survey of 30 Districts. PLoS One, 6, e24160. https://doi.org/10.1371/journal.pone.0024160

[4] Samal, J. (2017) A Review of Literature on Delays in Seeking Care for Tuberculosis in Different Indian States. BLDE University Journal Health Science, 16, 4-8. https://doi.org/10.4103/bjhs.bjhs_49_16

[5] GoI (2014) District Level Household and Facility Survey-IV. DLHFS. International Institute for Population Sciences (IIPS), Ministry of Health and Family Welfare, Mumbai.

[6] Prasad, B.M., Satyanarayana, S., Chadha, S.S., Das, A., Thapa, B., Mohanty, S., et al. (2016) Experience of Active Tuberculosis Case Finding in Nearly 5 Million Households in India. Public Health Action, 6, 15-18. https://doi.org/10.5588/pha.15.0035

[7] Thapa, B., Prasad, B.M., Chadha, S.S. and Tonsing, J. (2016) Serial Survey Shows Community Intervention May Contribute to Increase in Knowledge of Tuberculosis in 30 Districts of India. BMC Public Health, 16, 1155.

https://doi.org/10.1186/s12889-016-3807-1

[8] Kreuter, M.W., Black, W.J., Friend, L., Booker, A.C., Klump, P., Bobra, S., et al. (2006) Use of Computer Kiosks for Breast Cancer Education in Five Community Settings. Health Education and Behavior, 33, 625-642. https://doi.org/10.1177/1090198106290795

[9] Pendleton, B.F., Schrop, S.L., Ritter, C., Kinion, E.S., McCord, G., Cray, J.J., et al. (2010) Underserved Patients' Choice of Kiosk-Based Preventive Health Information. Family Medicine, 42, 488-495.

[10] Joshi, A., Perin, D.M.P. and Arora, M. (2013) Using Portable Health Information Kiosk to Assess Chronic Disease Burden in Remote Settings. Rural and Remote Health, 13, 2279.

[11] Lasky, T., Kogut, S., Campbell, S. and Risica, P.M. (2011) Computer Kiosks to Deliver Medication Information in the Pharmacy. Journal of Consumer Health on the 
Internet, 15, 347-360. https://doi.org/10.1080/15398285.2011.623579

[12] Porter, S.C., Cai, Z., Gribbons, W., Goldmann, D.A. and Kohane, I.S. (2004) The Asthma Kiosk: A Patient-Centered Technology for Collaborative Decision Support in the Emergency Department. Journal of the American Medical Informatics Association, 11, 458-467. https://doi.org/10.1197/jamia.M1569

[13] Orlando, M.S., Rothman, R.E., Woodfield, A., Gauvey-Kern, M., Peterson, S., Miller, T., et al. (2016) Public Health Information Delivery in the Emergency Department: Analysis of a Kiosk-Based Program. The Journal of Mergency Medicine, 50, 223-227.

[14] Teolis, M.G. (2010) A Medline Plus Kiosk Promoting Health Literacy. Journal of Consumer Health on the Internet, 14, 126-137. https://doi.org/10.1080/15398281003780966

[15] Radvan, D., Wiggers, J. and Hazell, T. (2004) Health C.H.I.P.s: Opportunistic Community Use of Computerized Health Information Programs. Health Education Research, 19, 581-590. https://doi.org/10.1093/her/cyg080

[16] Humphreys, J.S., Wakerman, J., Wells, R., Kuipers, P., Jones, J.A. and Entwistle, P. (2008) "Beyond Workforce": A Systemic Solution for Health Service Provision in Small Rural and Remote Communities. The Medical Journal of Australia, 188, S77-S80.

[17] Prasad, B.M., Satyanarayana, S. and Chadha, S.S. (2016) Lessions Learnt from Active Tuberculosis Case Finding in an Urban Slum Setting of Agra City, India. Indian Journal of Tuberculosis, 16, 199-202. https://doi.org/10.1016/j.ijtb.2016.08.006

[18] Zhang, H., Ehiri, J., Yang, H., Tang, S. and Li, Y. (2016) Impact of Community-Based DOT on Tuberculosis Treatment Outcomes: A Systematic Review and Meta Analysis. PLoS One, 11, e0147744. https://doi.org/10.1371/journal.pone.0147744

[19] Williams, P., Nicholas, D. and Huntington, P. (2003) Non Use of Health Information Kiosks Examined in an Information Needs Context. Health Information and Libraries Journal, 20, 95-103. https://doi.org/10.1046/j.1471-1842.2003.00428.x

[20] Gupta, M., Saibannavar, A.A. and Kumar, V. (2016) Household Symptomatic Contact Screening of Newly Diagnosed Sputum Smears Positive Tuberculosis Patients-An Effective Case Detection Tool. Lung India, 33, 159-162. https://doi.org/10.4103/0970-2113.177445

[21] Nair, D., Rajshekhar, N., Klinton, J.S., Watson, B., Velayutham, B., Tripathy, J.P., et al. (2016) Household Contact Screening and Yield of Tuberculosis Cases-A Clinic Based Study in Chennai, South India. PLoS One, 11, e0162090.

https://doi.org/10.1371/journal.pone.0162090

[22] GoI (2015) TB India 2015: Revised National TB Control Programme; Annual Status Report. Ministry of Health and Family Welfare, Central TB Division, New Delhi.

[23] Aggarwal, A.N., Gupta, D., Agarwal, R., Sethi, S., Thakur, J.S., Anjinappa, S.M., et al. (2015) Prevalence of Pulmonary Tuberculosis among Adults in a North Indian District. PLoS One, 10, e0117363. https://doi.org/10.1371/journal.pone.0117363

[24] Samal, J. (2016) Health Seeking Behaviour among Tuberculosis Patients in India: A Systematic Review. Journal of Clinical and Diagnostic Research, 10, No. 10. https://doi.org/10.7860/JCDR/2016/19678.8598 